\title{
CONSIDERAÇÕES SOBRE A RESSIGNIFICAÇÃO HERMENÊUTICO-FILOSÓFICA DA EXPERIÊNCIA FORMATIVA: Gadamer e o caráter ético e estético da educação*
}

\author{
CONSIDERATIONS ON HERMENEUTIC -PHILOSOPHICAL RESIGNIFICATION OF FORMA- \\ TIVE EXPERIENCE: Gadamer and the ethical and aesthetic character of education
}

\author{
CONSIDERACIONES SOBRE LA REDEFINICIÓN DE LA HERMENÉUTICA FILOSÓFICA-FORMATIVO \\ EXPERIENCIA: Gadamer y la educación ética y estética
}

Resumo: Este trabalho propõe uma reflexão sobre a natureza humana a partir de uma perspectiva hermenêutica, relacionando-a com a Ética e a Estética nos processos que permeiam a educação enquanto experiência de formação do humano. A tese do filósofo alemão Hans-Georg Gadamer, de que educar é educar-se, não só nos remete a uma reflexão sobre a natureza humana, como está na centralidade do problema formativo do mesmo. Problema esse que nas vias de solução deixa de ser gnosiológico ou mesmo epistemológico, passando a ser de caráter ontológico, ou seja, como compreendemos, levando em consideração que a noção de sujeito não mais está assentada no cogito cartesiano e nem nas faculdades do juízo kantiana. Entretanto, podemos observar que a maioria das teorias pedagógicas encontra sua gênese estruturante nessas noções já desconstruídas de sujeito, o que acentua a crise na educação. 0 sujeito, para Gadamer, agora é o Dasein, herdado de Heidegger e que, em sua visão, expressa melhor a natureza humana. Surge então a necessidade de refletir sobre essa natureza, tendo em vista a proposta de ressignificação da experiência formativa do humano pela educação, a partir de uma perspectiva ontológica, levando em conta a experiência estética como articulação para uma educação Ético-Estética.

Palavras-chave: Hermenêutica. Educação. Formação. Ética. Estética.

\begin{abstract}
This paper is a reflection claim about human nature from a hermeneutic perspective, relating it to the Ethics and Aesthetics in the processes that underlie education while training the human experience. The thesis of the German philosopher Hans-Georg Gadamer, that education is to educate yourself not only leads us to a reflection on human nature, as is the centrality of the problem of the same formation. This problem in ways that solution no longer gnosiologic epistemological or even becoming the ontological character, that is, as we understand, considering that the notion of subject is no longer seated in the Cartesian cogito nor the faculties of judgment Kant. However, we can observe that most pedagogical theories finds its genesis structuring these notions already deconstructed the subject, which accentuates the crisis in education. The subject, for Gadamer, is now Dasein, Heidegger's legacy and that, in his view, best expressed human nature. Then comes the need to reflect on this the crisis in education. The subject, for Gadamer, is now Dasein, Heidegger's legacy and that, in his view, best expressed human nature. Then comes the need to reflect on this nature, in view of the proposed redefinition of the human formative experience for education, from an ontological perspective, taking into account the aesthetic experience as an education articulation for Ethical and Aesthetic.
\end{abstract}

Keywords: Hermeneutics. Education. Training. Ethics. Aesthetics.

Resumen: Este trabajo tiene la intención de hacer una reflexión sobre la naturaleza humana desde una perspectiva hermenéutica, relacionándolo con la ética y la estética en el proceso de educación que impregnan durante la formación de la experiencia humana. La tesis del filósofo alemán Hans-Georg Gadamer, que la educación es educarse a si mismo no sólo nos lleva a una reflexión sobre la naturaleza humana, como está en el centro del problema de la misma formación. este problema de manera que la solución deja de ser gnosiológica o mismo epistemológica pasando a convertirse en carácter ontológico, es decir, a nuestro entender, teniendo en cuenta que la noción de sujeto ya no está sentado en el cogito cartesiano ni las facultades del juicio Kant. Sin embargo, podemos observar que la mayoría de las teorías pedagógicas encuentra su génesis estructural en estas nociones ya desconstruídas de sujeto, lo que acentúa la crisis en la educación. El sujeto, para Gadamer, es ahora Dasein, el legado de Heidegger y que, a su juício, representa mejor la naturaleza humana. Luego viene la necesidad de reflexionar sobre esta naturaleza, a la vista de la propuesta de redefinición de la experiencia formativa del humano por la educación, desde el punto de vista ontológico, teniendo en cuenta la experiencia estética como una articulación de la educación ética y estética.

Palabras clave: Hermenéutica. Educación. Formación. Ética. Estética

Trabalho premiado durante o XXIV Encontro do SEMIC, realizado na UFMA entre os dias 05 a 08 de novembro de 2012.

*Artigo recebido em dezembro 2012

Aprovado em fevereiro 2013 


\section{INTRODUÇÃO}

Umas das frases marxistas mais famosas, "Tudo que é sólido se desmancha no $a r^{\prime \prime}$ parece ter sua aplicação, ou por que não dizer, um tom profético, mesmo fora das rígidas paredes do marxismo. Refirimo-nos a crise da racionalidade científica moderna, crise essa que parecia distante ou mesmo algo impensável principalmente pela "solidez" do método racionalista. E se levarmos em consideração que esse modelo se tornou hegemônico desde o século XVI em uma crescente vertiginosa, essa crise seria mais impensável ainda. Mas, justamente essa crescente que resultou nos avanços, nas conquistas, na expansão do método, explicitou também as suas fragilidades e principalmente os seus limites, expondo à crise todas as concepções que nesse método estão estruturadas, inclusive a concepção moderna de sujeito, matriz constituinte de todos os modelos pedagógicos que estruturam os processos educacionais.

Se considerarmos as bases epistemológicas $^{2}$ das correntes pedagógicas, observaremos melhor a dimensão do problema. A primeira corrente pedagógica formulada é a Escola Tradicional, que tem como base epistemológica o racionalismo. A segunda se refere à Escola Nova, que se estrutura epistemologicamente no empirismo, cujo ideal do conhecimento advém das nossas experiências. A terceira corrente é o Tecnicismo, que tem como base o pragmatismo, e por último, aquela que seria a superação das anteriores, a transmissão crítica de conteúdos, apresenta como base epistemológica o Marxismo. Peter Sloterdijk (2002, p. 23) observa que a vertente marxista é uma variação do humanismo, como o cristianismo e o existencialismo também o são, remédios já utilizados frente à crise, que se mostraram teoricamente perfeitos mas efetivamente inócuos.

Diante dessa crise sem precedentes fez-se necessário repensar algumas questões, sem posturas dogmáticas ou mesmo fundamentalistas, e uma dessas foi pontuar a operação desse método nas ciências humanas, ou seja, questionar por que as chamadas ciências do espírito utilizaram sua gênese formativa o método das ciências da natureza? E quais foram as conseqüências desse equívoco na construção do conhecimento? A verdade está necessariamente ligada ao método? Essas e outras perguntas tentaram ser elucidadas neste trabalho, à luz das análises críticas de Hans-Georg Gadamer, pois a hermenêutica filosófica pensada por ele inaugura uma nova série de indagações e reflexões a partir do entendimento que o método desenvolvido pelas ciências naturais não guia a toda verdade, isto porque a verdade não tem relação necessariamente com o método.

O modelo pedagógico cientificista dá uma grande ênfase, nos processos educativos, ao desenvolvimento de competências e habilidades que favorecem apenas a dimensão cog- nitiva do aluno. Essa postura compromete a formação humana, haja vista que na experiência estética, por exemplo, a realidade pode ser apreendida pela sensibilidade. E ao gerar esse empobrecimento da formação ao privilegiar apenas a dimensão cognitiva do aluno, desconstrói também a experiência ética, pois os conteúdos se distanciam da experiência da vida, e ao se distanciar da sensibilidade, imaginação, faz com que a ética seja incompreensível na esfera da experiência humana.

Surge, assim, a proposta de pensar a educação dentro de uma perspectiva hermenêutica em que a experiência estética seja o elo de comunicação com a Ética, para uma formação livre e singular do humano.

Neste trabalho, estaremos percorrendo o caminho de algumas mudanças paradigmáticas operacionalizadas no pensamento moderno, a fim de alcançarmos o entendimento exato das críticas postuladas por Gadamer à racionalidade científica, bem como a mudança para a perspectiva ontológica. Estabelecemos como proposta uma educação Ético-Estética, em que os problemas advindos da formação possam ser equacionados.

\section{A CONCEPČ̃̃O ONTOLÓGICA- HERMENÊUTICA DO SER}

Gadamer, em suas investigações, avalia o processo do compreender sob uma perspectiva ontológica, não mais gnosiológica ou mesmo epistemológica como outrora. O cerne dessa mudança está no pensamento daquele que fora seu professor Martin Heidegger, a partir de uma nova concepção de "sujeito" que é o Dasein.

Heidegger, em seus estudos, observa que Parmênides teria descoberto o sentido do ser, e Platão o teria ocultado por buscar o sentido do ser nos entes. Logo, a proposta filosófica de Heidegger consiste em algo que fosse mais originário e fundamental, ou seja, a retomada da ontologia, pois a tradição filosófica produziu o esquecimento do ser.

Heidegger passa então a criticar a tradição filosófica, que em sua concepção é essencialista, pois confunde a idéia de "ser" e "ente" que resulta assim na divisão do ser em substância e acidente, como fez Aristóteles. Dessa caracterização surge a tendência de classificação e categorização do ente como se fosse o ser, como vai, por exemplo, ressaltar Descartes na divisão em res cogitans e res extensa. A autora Nadja Hermam (2002, p. 32) observa bem essas dicotomias:

A pergunta pelo ser é a mais antiga da filosofia, caminho aberto por Heráclito e Parmênides, pensadores gregos a partir dos quais Heidegger retoma sua investigação. Para os pré-socráticos não havia as dicotomias do ser, como transcendência e imanência, permanência e devir, realidade e aparência, pois o compreendem em sua raiz, pela unidade harmoniosa entre ser e devir. 
Nadja Hermam (2002, p. 32) ao destacar que "Platão promove o rompimento da harmonia original, quando formula a distinção entre pensamento e realidade", faz-nos perceber que desse equívoco platônico resultou uma sequência desordenada de equívocos outros ao ponto de Heidegger demonstrar em Ser e Tempo, nas palavras de Chris Lawn (2007, p. 13), que é possível interpretar o mundo sem um pré-entendimento. Notadamente contrário ao pensamento cartesiano, observa que o entendimento não é resolvido na privacidade da consciência, e sim através do nosso ser no mundo, ou seja, o Dasein.

O que difere, assim, o Dasein da consciência pensada por Descartes, pois o Dasein permite que compreendamos a experiência humana sem a necessidade de submetê-la a uma idéia de subjetividade, subjetividade essa, que por sua vez, está alicerçada em uma metafísica a qual à medida que dizia estudar o ser, propagava o seu esquecimento.

A Metafísica é um platonismo que só tem mudado a fachada, mas conserva as características primeiras, ou seja, de Platão até agora, com exceção de Nietzsche, não há nada novo, na visão de Heidegger (1989), tanto que, no primeiro capítulo de Ser e Tempo, o filósofo alemão observa que a história da filosofia é uma "recauchutagem", essa foi sem dúvida a melhor metáfora para descrever o que temos vivido, uma camada de teoria nova sob uma mesma e antiga estrutura, sempre que essa se desgasta.

Além do equívoco do sujeito cartesiano alicerçado no cogito, o sujeito kantiano sofre do mesmo mal. Mesmo com a pretensão de fazer uma revolução copernicana na filosofia, Kant só inverte o foco de uma proposição, ou seja, antes o foco estava no objeto e ele desloca para o sujeito, criando, assim, o sujeito transcendental, alicerçado nas faculdades do juízo, dando continuidade à dualidade entre o homem e o mundo já existente, onde nesse modelo de sujeito as análises continuam sendo subjetivas, alicerçadas em uma metafísica equivocada do ser.

É inegável pelo próprio Heidegger, a influência de Husserl e da fenomenologia pensada por ele nos seus escritos ${ }^{3}$. Entretanto, na sua obra Ser e Tempo, dedicada a Husserl, Heidegger faz uma "ontologia fundamental" e, ao fazê-lo, expõe os limites da fenomenologia.

Husserl, com a fenomenologia, pretendia uma superação entre o dualismo sujeito e objeto, onde o homem seria ao mesmo tempo sujeito e objeto. Para tanto, Husserl cria um modelo de consciência-fenômeno, como uma alternativa de superação do dualismo já citado. Entretanto esse modelo pensado por Husserl ainda está preso a uma compreensão subjetiva do Ser.

A fenomenologia seria então uma ferramenta para se apreender o sentido do Ser através da análise existencial do Dasein, ou seja, para compreender o Ser, nós fazemos por intermédio do Dasein. A proposta é investigar o Ser através daquilo que se mostra, logo, se faz necessária outra ferramenta para dar conta dessa interpretação, que é a hermenêutica, não a tradicional, mas sim uma hermenêutica da facticidade a qual compreender é interpretar, pensar o homem como Dasein o Ser-AÍ, dentro dos limites de sua existência.

Logo, com Heidegger temos uma base ontológica pela pergunta do sentido do Ser, e o problema hermenêutico da compreensão é redefinido a partir da pergunta de como se construiria essa compreensão fora do ponto de vista gnosiológico e epistemológico. Pontos de vistas esses que até então definiam os estudos sobre a compreensão e o conhecimento. Essa mudança da esfera gnosiológica e epistemológica para uma perspectiva hermenêutica é de suma importância, pois afeta diretamente a maioria das concepções educacionais que se alicerçam nos modelos de sujeitos pensados, principalmente pela epistemologia, e que já foram desconstruídos na contemporaneidade.

A hermenêutica da facticidade, que se propõe a dar conta desse problema, tem sua origem em Heidegger. Entretanto, é com Gadamer que ela se desenvolve ao status de uma hermenêutica filosófica, até porque Heidegger não tinha pretensão de aprofundamento dos estudos hermenêuticos, tanto que se "absteve de mencionar a hermenêutica em seus últimos trabalhos". (LAWN, 2007, p. 76).

Outra distinção importante a ser considerada é que Heidegger apresentava a "Linguagem" como "casa do Ser". Já para Gadamer o Ser não é somente a "casa", ele é "Linguagem", e dessa forma pode ser experimentado e compreendido, pois nessa perspectiva todas as formas de vida são linguagens e dessa forma podem efetivamente ser compreendidas. Logo, a linguagem no pensamento de Gadamer configura-se como a própria condição hermenêutica.

\section{DA HERMENÊUTICA HISTÓRICA À HERMENÊUTICA FILOSÓFICA}

Tornou-se um lugar comum a compreenssão do significado da hermenêutica, enquanto uma ciência da interpretação. Essa visão remete ao protestantismo, que descarta a forma alegórica de interpretação das escrituras, e estabelece uma interpretação literal da mesma. Para tanto, se faz valer de alguns procedimentos e técnicas próprios que dão origem a esse tipo de hermenêutica.

Vale, entretanto, ressaltar que esse termo já havia, na Grécia Antiga, se estabelecido, a partir do deus Hermes, que além de ser o deus do comércio, era também o deus que respondia pela interpretação, ou seja, quando os deuses do Olímpio se reuniam, cabia a Hermes a tarefa de interpretar seus desígnios frente os mortais ou mesmo outro deus.

A hermenêutica ganha status de filosófica no século XIX, com Friedrich Schleiermacher, 
que começa a problematizá-la, levando em consideração que o princípio da hermenêutica antiga estava equivocado à mediada que estabelecia que "a possibilidade de entendimento de um texto era maior do que a possibilidade do não entendimento do mesmo". (LAWN, 2007 , p. 67). Schleiermacher observa o grande equívoco desse princípio, pois o entendimento não pode ser dado como certo, sem que antes seja pesquisado e testado.

Schleiermacher estabelece com sua hermenêutica os limites para a compreensão, pois insere no discurso hermenêutico um caráter epistemológico, bem como um caráter psicológico em torno da questão da interpretação, o que Gadamer observa como um caminho equivocado trilhado pelo filósofo hermeneuta Schleiermacher. Entretanto, essas e outras limitações não tiram o brilho do trabalho de Schleiermacher, responsável por categorizar a "aplicabilidade da hermenêutica como universal" (LAWN, 2007, p. 72).

Já no século XIX um importante nome dentro das mudanças operacionalizada na hermenêutica foi Wilhelm Dilthey que vai influenciar tanto Heidegger quanto Gadamer, não só pela perspectiva hermenêutica, mas também por ser dele a crítica da utilização do método das ciências naturais nas ciências humanas. Vale, portanto, a ressalva que essa "divisão" entre as ciências foi igualmente pensada por ele.

Ainda sobre a proposta hermenêutica de Dilthey convém destacar seu "distanciamento da interpretação psicológica" pensada por Schleiermacher (LAWN, 2007, p. 75), acentuando elementos históricos no contexto da interpretação, pois, para ele, o conhecimento hermenêutico está conectado ao passado.

Entendendo que nessa época a discussão é de cunho epistemológico, Dilthey desenvolve uma crítica a um único tipo de compreensão, via lógica transcendental do sujeito kantiano. Para ele, no ato de compreender se fazem necessários elementos históricos, pois nós somos irredimivelmente históricos, e para tanto o procedimento hermenêutico se faz assim necessário. Dilthey observa ainda que todo o conhecimento tem uma dimensão histórica a ser analisada.

A hermenêutica pensada por Dilthey de alguma forma estava presa ainda a uma perspectiva metodológica das ciências humanas. Logo, para o próprio Gadamer, foi Heidegger quem "genuinamente revelou a historicidade do entendimento", pois vinculou a hermenêutica à interpretação do sentido do ser. (LAWN, 2007, p. 77).

Heidegger parte da temporalidade e historicidade do ser para investigar o próprio ser, reconhecendo que a facticidade era mais importante que a consciência. Daí a necessidade de repensar a hermenêutica que passa, assim, a ser fenomenológica para essa tarefa de compreensão do Dasein. Para Heidegger (2002, p. 34) compreender não é apenas uma dentre muitas facetas do sujeito, "compreender é o modo de ser do Dasein".

O homem compreende o mundo pela linguagem, que se constitui como um projeto de interpretação, por essa razão a hermenêutica proposta por Gadamer pretende observar que o conhecimento não é fruto de uma pura subjetividade transcendental, ele se dá em duas instâncias: a linguagem, como já citado, e a historicidade.

Compreendendo que essa relação linguagem e historicidade são muito próximas, uma vez que temos uma consciência histórica que se realiza na linguagem. Essa relevância da linguagem na compreensão, como bem observa Nadja Hermann (2002, p. 73), dá à hermenêutica a "pretensão de universalidade". Eis por que o fenômeno da compreensão só pode ser pensado no médium da linguagem e enquanto tal se realiza no horizonte do diálogo.

\section{A HERMENÊUTICA E SUA RELAÇÃo COM A ÉTICA E A ESTÉTICA NO UNIVERSO EDUCACIONAL}

Ao pensar a educação dentro de uma perspectiva hermenêutica filosófica, faremos a proposta de fuga do lugar comum, onde esse tema tem se exaurido nos conceitos pedagógicos e se perdido no meio deles. Caracterizar essa pesquisa como parte constitutiva de uma filosofia da educação, também não cremos que seja o caso, pois a filosofia antes de tudo é uma criadora de conceitos, lembrando Deleuze e Guattari (2004, p. 13). Logo, seria mais coerente uma "filosofia na educação", que nos permitisse pensar a educação nos despojando das nossas falsas certezas.

Para tanto, faz-se necessário encarar alguns problemas que podem se constituir como um entrave ante esta pesquisa, que, por falta de espaço, abordaremos inicialmente dois. O primeiro é de caráter, digamos, paradigmático, produzido pela interpretação da obra "A Reprodução", dos sociólogos franceses Bourdieu e Passeron (1975) e, principalmente, pelos pensadores pessimistas modernos da educação, que deles fazem coro, pois na sua obra " $A$ Reprodução" consideraram que a escola reproduz a sociedade em uma instância econômica e social. Logo, na visão de alguns pensadores, fica de alguma forma comprometida toda a possibilidade de qualquer discussão sobre educação, pois tudo que for feito enquanto tentativa de mudança na educação esbarraria no caráter reprodutivo dela.

No livro Pedagogia da práxis, Moacir Gadotti (1998, p. 73) abre caminho frente a esse engessamento, quando afirma que se a educação reproduz a sociedade, ela poderia, por sua vez, transformar o que ela reproduz, afirmativa essa que nós também creditamos desde que a educação se transforme primeiro, ou pelo menos, usando um conceito do filosofo francês Gilles Deleuze, apresente linhas de fugas frente aos problemas advindos da educação. 
O segundo problema estaria ancorado na dúvida sobre a contribuição que a hermenêutica poderia dar para a educação. Nadja Hermann, no seu livro "Hermenêutica e educação", ao observar que a hermenêutica é "outra racionalidade, onde a verdade não está nos dados empíricos nem na verdade absoluta"( HERMANN, 2002, p. 83), e que a hermenêutica conduz a "verdade pelas condições humanas da linguagem" (HERMANN, 2002, p. 83), contribui de forma decisiva frente a esse impasse, pois ao partir de outra racionalidade, abre espaço para novos caminhos frente aos desafios educacionais vigente.

Vale a ressalva que as próprias atuais condições da educação como uma das áreas do saber moderno mais contestada atualmente, por não conseguir responder aos anseios de uma sociedade que, ao mesmo tempo se caracteriza pelas constantes transformações, se alarma com as crescentes patologias sociais que ameaçam o seu bem estar. Este estado de alarme tem se tornado ainda mais ativado à medida que observamos das instituições escolares, em tese responsáveis pela formação, brotarem comportamentos violentos e discriminatórios, como exemplo o bullying, citando um de muitos problemas da escola.

Esses problemas por si sós justificariam uma pesquisa que repensasse a educação fora dos paradigmas que ao longo dos anos a estruturaram, imprimindo nas ciências que estudam a educação a mesma visão de mundo positivista, ou seja, de discriminar, classificar, identificar as coisas já presumindo o domínio sobre elas, e elaborando teorias que comunguem menor quantidade de tempo e economia financeira para as políticas educacionais.

Diante desse desafio, atentemos às contribuições de Gadamer (2000, p. 10) para educação, posteriormente relacionando-as com a ética e a estética. Para ele, só existe possibilidade de aprender por meio da "conversação do diálogo", diálogo esse entre professor e aluno, haja vista que o modelo pedagógico cientificista deslocou esse diálogo para professor/ ciência, professor/conteúdos, comprometendo a relação ensino/aprendizagem: Vejamos a importância dada ao diálogo nas palavras do próprio Gadamer (2002, p. 247):

O que é um diálogo? De certo que com isso pensamos num processo entre pessoas, que apesar de toda sua amplidão e infinitude potencial possui uma unidade própria e um âmbito fechado. Um diálogo é, para nós, aquilo que deixou uma marca. O que perfaz, um verdadeiro não é termos experimentados algo novo mas termos encontrado no outro algo que ainda não havíamos encontrado em nossa própria experiência de mundo. Aquilo que movia os filósofos a criticar o pensamento monológico é o mesmo que experimenta o indivíduo em si mesmo. O diálogo possui uma força transformadora. Onde um diálogo teve êxito ficou algo para nós e em nós que nos transformou. O diálogo possui, assim uma grande proximidade com a amizade. É só no diálogo (e no rir juntos que funciona como um entendimento tácito trasbordante) que os amigos podem encontrar-se e construir aquela espécie de comunhão onde cada qual continua sendo o mesmo para o outro porque ambos encontram o outro e encontram a si mesmo no outro.

Nadja Hermann (2002, p. 95) observa que "a educação é o lugar do diálogo", pois o diálogo se constitui na possibilidade de experimentar nossa singularidade e a experiência do outro, com suas objeções ou sua aprovação. Esse diálogo permite ainda, pela palavra e reflexão, um conduzir a um processo de formação pessoal que ultrapassa a mera apropriação técnica dos conhecimentos.

Esse conceito de formação que ocupa com relevância o pensamento de Gadamer está intimamente ligado aos ideais da educação que se relacionam com a aprendizagem e competências pessoais e a cultura; tem profunda relação com a ética, que no pensamento cientificista moderno foi desprezado.

Para Gadamer (2000, p. 17), não se pode formar para coisa alguma, muito menos para compreender, pois a compreensão advém da própria abertura para ela, uma vez que ao "dialogar nos formamos", haja vista que fazemos uso da compreensão em tal tarefa. Logo, compreender é um aspecto importante da formação e aponta para a solidariedade de compreender o outro neste processo de formação, que resgata o sentido ético na transmissão de conteúdos nos processos educacionais. Entretanto, assim como o pensamento cientificista moderno, o humano se fechou nas suas convicções e nas supostas autoridades delas, e fazendo da ética um conteúdo científico a ser aprendido, e não vivido como uma prática de vida. Basta observar o próprio universo escolar em que a violência se manifesta em todas as escolas do mundo ocidental e de maneira mais intensa nos Estados Unidos, onde os professores tomam atitudes extremas de instalar sistemas de seguranças contra os estudantes, e o bullying se tornou algo recorrente.

Dessa forma, a hermenêutica, enquanto uma experiência de abertura, remete-nos a uma reflexão ética, tão desvalorizada em nossos dias que, segundo Emmanuel Lévinas (2010, p. 42), constitui-se como "a filosofia primeira", ou seja, dessa relação com o outro, surge a verdadeira reflexão filosófica, pois parte de uma filosofia da práxis, haja vista que está ancorada no mundo prático da vida, e nada é tão prático quanto a relação com o outro, experiência pouco priorizada em nossos dias.

A experiência de abertura proposta pela hermenêutica de Gadamer contrasta com uma sociedade marcada, ou por que não dizer, constituída pela competição e ausência de solidariedade, onde as técnicas cientificistas trazem uma impessoalidade nas relações. Esse aspecto da sociedade aponta não só para a falência do método quanto para um treinamento antissolidariedade, mas também e, principalmente, para o fechamento do "EU" em si, sem abertura para o diálogo, causando um entrave no processo de formação, e principalmente na incapacidade de reconhecimento do outro. Basta olharmos ao nosso redor e observarmos 
na prática social, assassinatos cometidos pela incapacidade de dialogo, e de uma alteridade.

Pensar hermenêutica na relação com a educação é pensar enquanto uma experiência de abertura, que dentre outras coisas supera a relação absolutista entre sujeito e objeto, onde o sujeito domina o objeto. Esta relação pode ser vista também na pedagogia cientificista. Esta experiência proposta por Gadamer está ancorada na sua tese que "educar é educarse" (GADAMER, 2000, p. 11). Nadja Hermann observa que isto implica em "apreciar a posição do outro, respeitar as capacidades e limites do aluno" (HERMANN, 2002, p. 85). Este ensinar na escuta do outro seria fomentar no aluno um sentido para ser e, principalmente, vir a ser, pois ao mesmo tempo este aluno é uma individualidade é um ser-com, ou seja, ele o é com as pessoas e as coisas, o que nos remete a um aspecto ético, não pelo conteúdo cientificista, mas pela prática de relação com o outro.

Para Gadamer, educar também "é estar em casa" (GADAMER, 2000, p. 47). Isto nos remete a algumas considerações: primeiro, ninguém é estranho em sua própria casa; segundo, estar em casa nos remete a ideia de semelhanças, de princípios comuns. Essa tese aponta ao panorama estético no universo educacional. Vejamos a aplicabilidade dessa tese na educação. Gadamer observa que o Iluminismo descaracterizou a ideia de preconceito, atestando como algo negativo. Entretanto, toda nossa compreensão advém dos nossos pré-conceitos relegados como negativos também pela pedagogia cientificista.

Se educar é estar em casa fazendo do estranho algo familiar, isso tem relação direta com nossos pré-conceitos. A linguagem nos permite uma pré-compreensão dos símbolos linguísticos do mundo. Por exemplo, podemos perguntar a um adolescente ou mesmo a um adulto, o que seja ética e, posteriormente, teremos respostas preconceituosas, imediatamente descartadas pela pedagogia cientificista, que ao invés de transformar o estranho no familiar, mantém a estranheza do conceito, impossibilitando assim a abertura do diálogo, que é imprescindível para a formação.

Nietzsche $(2008$, p. 118) observa na sua segunda consideração intempestiva que "o jovem começará sua educação apreendendo o que é cultura, não aprenderá o que é vida, com maior razão ignorará a experiência da vida", como se as teorias não partissem do vivido e sim de uma autoridade cientifica. Estar em casa é estabelecer vínculos de semelhanças, princípios comuns com o conteúdo via diálogo com o professor.

Gadamer, em Verdade e Método, ao propor examinar de que modo a experiência associada ao conhecimento estético constitui-se como um novo paradigma, contrapondo-se aos limites impostos pelo positivismo científico através do método, observa o domínio do estético como uma experiência de verdade, e, portanto, uma forma de conhecimento do mundo.
Logo, evocamos a experiência estética no processo de formação educacional em duas vias, sendo a primeira a sensibilização ao conteúdo, haja vista que o conceito de política em uma aula para jovens é melhor recebido via uma música ou um filme etc, do que já introduzindo o texto filosófico, como bem observa Silvio Galo (2007) por exemplo. Na segunda via, a experiência estética se apresenta como resistência às formas de saberes já existentes e consolidados, como uma experiência de abertura mediada pela hermenêutica a novos conceitos, objetivando alcançar todo potencial do Homo Ludens como bem observou Huizinga (1999) no seu pensamento. Podemos assim observar a partir do lúdico, que não somos apenas uma racionalidade (Homo Sapiens) e nem aquele que possui unicamente a capacidade de transformar a natureza pelo trabalho (Homo Faber). Somos, principalmente, dotados de uma capacidade de jogar, de criar e interagir com o lúdico, e ao fazermos isso, escapamos das relações cristalizadas de poder que aprisionam o pensamento.

Gadamer (2007, p. 154) observa o jogo "como o modo de ser da própria obra de arte", partindo de uma fundamentação ontológica; dessa forma a estética pensada por Gadamer escapa da esteticização do mundo da vida, onde a estética perdera toda sua capacidade crítica e dessa forma seu sentido. O jogo, em Gadamer, ganha uma dimensão diferente ao transformar-se em experiência que transforma, onde quem joga se vê jogando e, esse jogo, perpassa o seu ser transformando-o. Essa transformação é propiciada pela experiência da obra de arte onde "algo se torna uma outra coisa, de uma só vez e como um todo, de maneira que essa outra coisa em que se transformou passa a constituir seu verdadeiro ser, em face do qual seu ser anterior é nulo" (GADAMER, 2007, p. 166). Dessa forma, pensar a estética a partir da hermenêutica filosófica em uma relação com educação, permite-nos inferir a possibilidade de fuga do lugar comum propiciado pelo modelo vigente oriundo do pensamento cientificista, e o alcance de novas possibilidades frente ao conhecimento.

\section{CONSIDERAÇÕES FINAIS}

Observar a hermenêutica filosófica como outra racionalidade nos permite considerar outros caminhos que essa outra racionalidade pode trilhar. Caminhos esses que não necessariamente nunca haviam sido trilhados, mas que foram, entretanto, por alguma razão abandonados ainda no seu início, pois sempre caminhos mais curtos foram buscados, por serem menos densos, e principalmente, porque ao longo da caminhada distraiam os caminhantes com paisagens que, no fundo, tiraram a atenção do real, que é para onde caminhamos.

Ética e Estética são temas ultrapassados na filosofia? Não pensamos assim, pelo contrário, são temas atuais. O primeiro é a condi- 
ção de possibilidade da continuidade da existência do gênero humano, como bem observa Gadamer, pois liberta-nos de toda transcendência metafísica e reconstrói a crença nesse mundo, colocando nosso pensamento nele com a esperança de transformá-lo, que é tudo que a nossa geração precisa. O segundo, como já abordado, é o que possibilita uma experiência de resistência ao modelo de pensamento vigente, pois a experiência estética libera as lógicas das relações, o "ser" para o "vir-a-ser", uma vez que desconstrói todo determinismo que caracteriza o discurso científico.

Por fim, trazer a ética e a estética à luz da hermenêutica filosófica e relacioná-la a educação é uma tentativa de criação de linhas de fuga que possa a educação transformá-la, pois a consistência do modelo cientificista concerne justamente em atrelar-se à educação, e dessa fazer seu caminho, e do produto dela, quer sejam as descobertas fruto da técnica, quer sejam as contradições que a educação tem ajudado a consolidar, as "paisagens" que por ora nos enganam, por outra nos distrai, impedindo-nos de enxergar para onde se caminha.

\section{NOTAS}

1. Frase extraída do "Manifesto Comunista" que a partir do artigo do crítico literário e cientista político, Marshall Berman em 1982 sobre o mesmo título da frase destacada, passou a caracterizar a complexidade dialética, pensada nesse trabalho de igual forma em relação ao método, na medida em que propagava seus avanços e expunha consequentemente seus limites e fragilidades.

2. As compreensões das bases epistemológicas presentes neste trabalho se estruturam em duas produções: o artigo "Pressupostos Filosóficos - Epistemológicos da avaliação educacional" (www.unicap.br/Arte/ler.php?art_cod=2456) e o artigo de Dermeval Saviane "As concepções pedagógicas na historia da educação brasileira" (http://www.histedbr.fae.unicamp.br/navegando/artigos_pdf/Dermeval_Saviani_artigo.pdf), por conta disso haverá discordâncias em determinadas bases epistemológicas e suas respectivas correntes pedagógicas.

3. Tanto que ele dedica Ser e Tempo a Edmund Husserl "com amizade e veneração"

\section{REFERÊNCIAS}

AGUILAR, Luis Armando. Conversar para aprender Gadamer y la educación. Revista Electrónica Sinéctica, n. 23, p. 11-18, agosto/ enero, 2004, Disponível em: <http://portal. iteso.mx/portal/page/portal/Sinectica/ Historico/Numeros anteriores05/023/23\%20 Luis\%20Armando\%20Aguilar-Mapas.pdf > . Acesso em: 23 mar. 2012.

BOURDIEU, P; PASSERON, J. C. A reprodução: elementos para uma teoria do sistema de ensino. Rio de Janeiro: Francisco Alves, 1975.

CERLETTI, Alejandro. O ensino de filosofia como problema filosófico. Belo Horizonte: Autêntica Editora, 2009.

DELEUZE, Gilles; GUATTARI, Félix. O que é filosofia? 2.ed. Rio de Janeiro: Editora 34, 2004.

FREIRE, Paulo. Educação e mudança. 34.ed. São Paulo: Paz e Terra, 2011.

GADAMER, Hans-Georg. La educación es educarse. Barcelona: Ediciones Paidós, 2000.

. Verdade e Método I: traços

fundamentais de uma hermenêutica filosófica. Trad. Flávio P. Meurer. 8.ed. Petrópolis: Vozes, 2007.

- Verdade e método II: complementos e índice. Trad. Ênio P. Giachini. Petropolis: Vozes, 2002.

GADOTTI, Moacir. Pedagogia da práxis. 2.ed., São Paulo: Cortez, 1998.

GALLO, S. A filosofia e seu ensino: conceito e transversalidade. In: SILVEIRA, R. J T; GOTO, R. (Org.). Filosofia no ensino médio: temas, problemas e propostas. São Paulo: Edições Loyola, 2007.

HEIDEGGER, Martin. Ser e Tempo I. Trad. Márcia de Sá Cavalcante. 3.ed. Petrópolis: Vozes, 1989.

HERMANN, Nadja. Hermenêutica e Educação. Rio de Janeiro: DP \& A, 2002. Coleção [o que você precisa saber sobre...].

HUIZINGA, Johan. Homo ludens: o jogo como elemento da cultura. São Paulo: Perspectiva, 1999.

LEVINAS, Emmanuel. Ética e Infinito. Lisboa/ Portugal: Edição 70, 2010.

KAHLMEYER-MERTENS, Roberto S. Heidegger \& a educação. Belo Horizonte: Autêntica Editora, 2008. (Coleção Pensadores \& Educação).

LAWN, Chris. Compreender Gadamer. Trad. Hélio Magri Filho. Petrópolis: Vozes, 2007.

NIETZSCHE, F. Segunda consideração intempestiva: da utilidade e do inconveniente da história para a vida. Trad. Antônio Carlos Braga e Ciro Mioranza. São Paulo: Ed. Escala, 2008.

SLOTERDIJK, Peter. Regras para o parque humano: uma proposta à carta de Heidegger sobre o humanismo. São Paulo: Estação Liberdade, 2000. 